\title{
Front Matter: Volume 10464
}

, "Front Matter: Volume 10464," Proc. SPIE 10464, AOPC 2017: Fiber Optic Sensing and Optical Communications, 1046401 (3 January 2018); doi: 10.1117/12.2296008

SPIE. Event: Applied Optics and Photonics China (AOPC2017), 2017, Beijing, China 


\title{
AOPC 2017: Fiber Optic Sensing and Optical Communications
}

\author{
Zi-Sen Zhao \\ Leping Wei \\ Yanbiao Liao \\ Weixu Zhang \\ Desheng Jiang \\ Wei Wang \\ Kenneth T. V. Grattan \\ Editors
}

\section{4-6 June 2017}

Beijing China

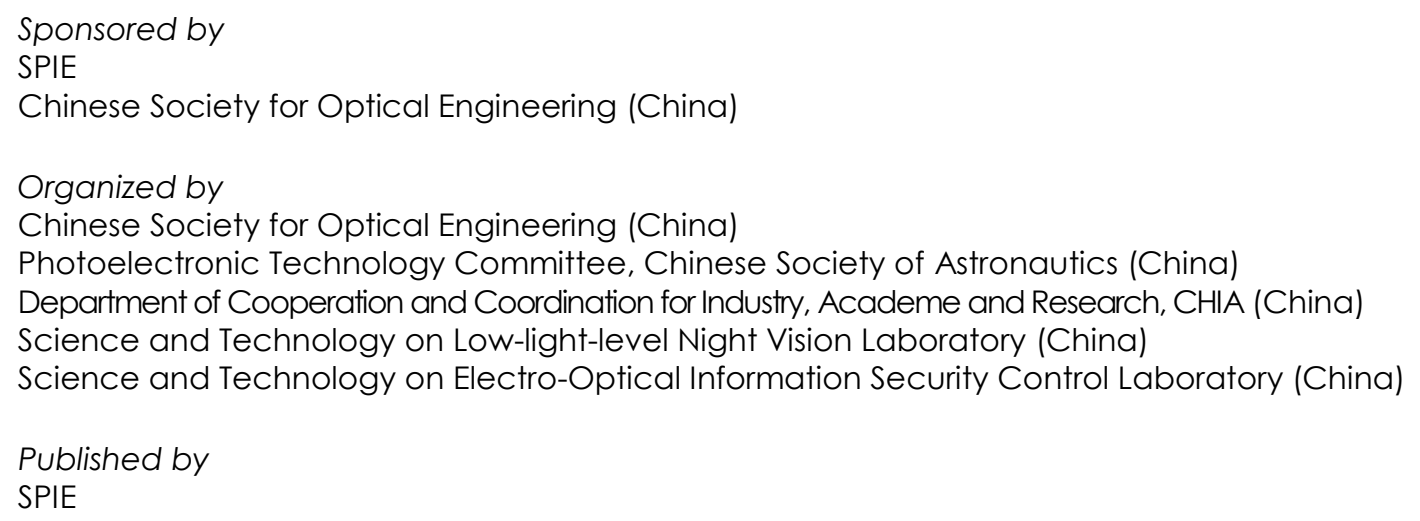

Volume 10464 
The papers in this volume were part of the technical conference cited on the cover and title page. Papers were selected and subject to review by the editors and conference program committee. Some conference presentations may not be available for publication. Additional papers and presentation recordings may be available online in the SPIE Digital Library at SPIEDigitalLibrary.org.

The papers reflect the work and thoughts of the authors and are published herein as submitted. The publisher is not responsible for the validity of the information or for any outcomes resulting from reliance thereon.

Please use the following format to cite material from these proceedings:

Author(s), "Title of Paper," in AOPC 2017: Fiber Optic Sensing and Optical Communications, edited by Zi-Sen Zhao, Leping Wei, Yanbiao Liao, Weixu Zhang, Desheng Jiang, Wei Wang, Kenneth T. V. Grattan, Proceedings of SPIE Vol. 10464 (SPIE, Bellingham, WA, 2017) Seven-digit Article CID Number.

ISSN: 0277-786X

ISSN: 1996-756X (electronic)

ISBN: 9781510614093

ISBN: 9781510614109 (electronic)

Published by

SPIE

P.O. Box 10, Bellingham, Washington 98227-0010 USA

Telephone +1 3606763290 (Pacific Time) · Fax +1 3606471445

SPIE.org

Copyright @ 2017, Society of Photo-Optical Instrumentation Engineers.

Copying of material in this book for internal or personal use, or for the internal or personal use of specific clients, beyond the fair use provisions granted by the U.S. Copyright Law is authorized by SPIE subject to payment of copying fees. The Transactional Reporting Service base fee for this volume is $\$ 18.00$ per article (or portion thereof), which should be paid directly to the Copyright Clearance Center (CCC), 222 Rosewood Drive, Danvers, MA 01923. Payment may also be made electronically through CCC Online at copyright.com. Other copying for republication, resale, advertising or promotion, or any form of systematic or multiple reproduction of any material in this book is prohibited except with permission in writing from the publisher. The CCC fee code is 0277$786 \mathrm{X} / 17 / \$ 18.00$

Printed in the United States of America.

Publication of record for individual papers is online in the SPIE Digital Library.

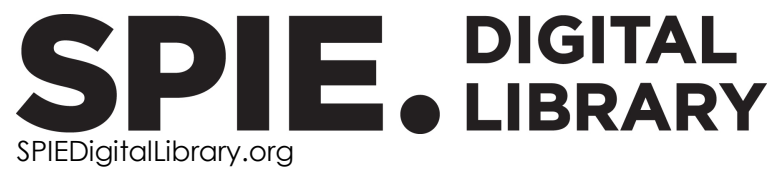

Paper Numbering: Proceedings of SPIE follow an e-First publication model. A unique citation identifier (CID) number is assigned to each article at the time of publication. Utilization of CIDs allows articles to be fully citable as soon as they are published online, and connects the same identifier to all online and print versions of the publication. SPIE uses a seven-digit CID article numbering system structured as follows:

- The first five digits correspond to the SPIE volume number.

- The last two digits indicate publication order within the volume using a Base 36 numbering system employing both numerals and letters. These two-number sets start with 00, 01, 02, 03, 04, 05, 06, 07, 08, 09, OA, OB ... 0Z, followed by 10-1Z, 20-2Z, etc. The CID Number appears on each page of the manuscript. 


\title{
Contents
}

\author{
ix Authors \\ xiii Conference Committee \\ $\mathrm{xV}$ Introduction
}

FIBER OPTIC SENSING AND OPTICAL COMMUNICATIONS

1046402 Influence of optical dome for airborne laser communication beam far-field divergence [10464-1]

1046403 Research on the novel FBG detection system for temperature and strain field distribution [10464-2]

1046404 A high spatial resolution distributed optical fiber grating sensing system based on OFDR [10464-4]

1046405 Perturbation theory and the longitudinal relaxation time $\mathrm{T}_{1}$ measurement for spin exchange optical polarized ${ }^{129} \mathrm{Xe}[10464-6]$

1046406 Three layers multi-granularity OCDM switching system based on learning-stateful PCE [10464-7]

1046407 Nonlinear optical response of a new Si-Ge waveguides with mid-infrared using femtosecond optical pulses [10464-8]

1046408 Refractive index and curvature sensitivity of LPFG inscribed in few-modes fiber [10464-10]

1046409 Information hiding technology and application analysis based on decimal expansion of irrational numbers [10464-11]

10464 OA Research on performance of three-layer MG-OXC system based on MLAG and OCDM [10464-12]

10464 OB Deduction of HiBi-PCF-LM interference spectrum equation with a independent probe and the influence of sensor length size [10464-13]

10464 OC Instrument for all-fiber structure measurement of ultra-low turbidity by using single photon detection technique [10464-14]

10464 OD A compact fiber sensor based on the high birefringence polarization maintaining fiber for simultaneous strain and temperature measurement [10464-15]

10464 OE Temperature sensitivity of LPFG inscribed in few modes fiber [10464-16] 
10464 OF Three-tier multi-granularity switching system based on PCE [10464-17]

10464 OG Changes of quantum state of polarization in coexistence scheme of quantum-classical signal [10464-19]

$10464 \mathrm{OH} \quad$ Study on the performance of quantum key distribution scheme with the single photon frequency up-conversion detector [10464-20]

$10464 \mathrm{Ol} \quad$ Applications in bridge structure health monitoring using distributed fiber sensing [10464-22]

10464 0J The design of a signal processing system for CCD star sensor [10464-23]

10464 OK Health monitoring of unmanned aerial vehicle based on optical fiber sensor array [10464-24]

$10464 \mathrm{OL} \quad$ A frequency-doubling microwave photonic phase shifter based on dual-polarization MZM [10464-25]

10464 OM A new quantum private comparison protocol [10464-27]

10464 ON Fiber optic refractive index sensor using optofluidic anti-resonant reflecting guidance [10464-28]

1046400 Research of hydroelectric generating set low-frequency vibration monitoring system based on optical fiber sensing [10464-50]

10464 OP Performance analysis of spin-oscillator system based on Simulink [10464-55]

$104640 Q \quad$ A cost-effective and reliable method for Brillovin optical time domain analysis [10464-56]

10464 OR Progress on single-frequency fiber lasers for sensing technology [10464-57]

10464 OS Distributed FBG sensors apply in spacecraft health monitoring [10464-58]

10464 OT Dual-wavelength single-frequency Erbium-doped ring fiber laser for high-resolution temperature and strain sensing [10464-60]

10464 OU Ad hoc laser networks component technology for modular spacecraft [10464-61]

10464 OV Modeling and analysis of laser active interference optical path [10464-70]

10464 OW A method for velocity signal reconstruction of AFDISAR/PDV based on crazy-climber algorithm [10464-71]

10464 OX Long distance $\Phi$-OTDR system based on Raman and EDFA synthetic amplification [10464-72]

10464 OY Off-resonance laser frequency stabilization method by Faraday rotation spectroscopy using acoustic-optic modulator [10464-73]

$10464 \mathrm{OZ}$ Study of the technics of coating stripping and FBG writing on polyimide fiber [10464-74] 
1046410 A buried intrusion monitoring system based on high sensitivity optical fiber geophone [10464-76]

1046411 The design of photoelectric signal processing system for a nuclear magnetic resonance gyroscope based on FPGA [10464-77]

1046412 Monitoring of bolt clamping force at high temperatures using metal-packaged regenerated fiber Bragg grating strain sensors [10464-78]

1046413 Orthogonal demodulation phase: shifting design of optical fiber hydrophone based on Hilbert transform [10464-79]

1046414 A low noise photoelectric signal acquisition system applying in nuclear magnetic resonance gyroscope [10464-80]

1046415 An intrusion detection system based on fiber hydrophone [10464-81]

1046416 Study of the characteristics about the digital holography with spherical and plane reference wave [10464-82]

1046417 Study of LED layout in indoor visible light communication and performance analysis [10464-83]

1046418 The variance of angle-of-arrival fluctuation of partially coherent Gaussian-Schell Model beam propagations in slant atmospheric turbulence [10464-84]

1046419 Real time distributed temperature measurement of the gain fiber in all-fiber laser employing OFDR technology [10464-86]

10464 1A Research on influence factors of flashing light source measurement [10464-87]

10464 1B Effect of spherical nonuniform distribute magnetic field on FOG [10464-88]

10464 1C Simultaneous measurement of temperature and strain based on all-fiber Fabry-Perot sensor [10464-89]

10464 ID Adaptive elimination of optical fiber transmission noise in fiber ocean bottom seismic system [10464-90]

$10464 \mathrm{IE} \quad$ Balloon-like singlemode-tapered multimode-singlemode fiber structure for refractive index sensing [10464-91]

10464 IF Microwave photonic frequency downconverter based on single sideband modulation [10464-92]

10464 1G Field test investigation of high sensitivity fiber optic seismic geophone [10464-93]

$10464 \mathrm{lH}$ An interferometric fiber optic hydrophone with large upper limit of dynamic range [10464-94]

1046411 Features extraction algorithm about typical railway perimeter intrusion event [10464-95] 
$104641 \mathrm{~J}$ A high sensitivity all-fiber temperature sensor based on SPS fiber structure-based Sagnac loop [10464-96]

10464 IK Rayleigh scattering based distributed optical fiber sensing [10464-97]

$10464 \mathrm{lL} \quad$ Research on temperature dependent mean wavelength stability of Erbium-doped fiber super fluorescent source for fiber optic gyroscopes [10464-98]

10464 1M Design of fiber optic F-P cavity pressure sensor based on corrugated diaphragm [10464-99]

10464 1N Design of the flame detector based on pyroelectric infrared sensor [10464-101]

1046410 Towed solid fiber streamer research on acoustic property [10464-102]

10464 IP Degeneracy and splitting of defect modes in one-dimensional symmetric photonic crystal [10464-103]

$104641 Q \quad$ An optical fiber expendable seawater temperature/depth profile sensor [10464-104]

10464 IR The seam visual tracking method for large structures [10464-106]

10464 is Hybrid fiber optic interferometers for temperature and strain measurements [10464-107]

$104641 \mathrm{~T}$ Fiber-optic dosimeters for radiation therapy [10464-108]

$104641 \mathrm{U}$ Ultra-wideband microwave photonic link based on single-sideband modulation [10464-109]

10464 IV Holding-time-aware asymmetric spectrum allocation in virtual optical networks [10464-110]

10464 IW A long distance voice transmission system based on the white light LED [10464-111]

10464 IY Research on propane leak detection system and device based on mid infrared laser [10464-114]

1046412 A temperature sensor based on Fresnel reflection on a collimator [10464-115]

1046420 Effective distance adaptation traffic dispatching in software defined IP over optical network [10464-117]

1046421 Multi-domain service dispatching scheme based on SDON virtualized network [10464-118]

1046422 A fiber Bragg grating acceleration sensor for ground surveillance [10464-119]

1046423 A multi-function and high precision submarine optical fiber monitor [10464-121]

1046424 Multi-layer service function chaining scheduling based on auxiliary graph in IP over optical network [10464-122]

1046425 The routing, modulation level, and spectrum allocation algorithm in the virtual optical network mapping [10464-123] 
1046426 High resolution 3C fiber laser micro-seismic geophone array for cross-well seismic [10464-125]

1046427 Transmission properties of defect mode in one-dimensional symmetry photonic crystal under one-way stress [10464-127]

1046428 Environmental and reliability test of FBG based geophone as geophysical exploration instrument [10464-129]

1046429 Nonuniform distribution of phase noise in distributed acoustic sensing based on phasesensitive OTDR [10464-130]

10464 2A Numerical simulation of the photon absorption cross-section of ${ }^{87} \mathrm{Rb}$ D1 line [10464-180]

10464 2B Walkaway-VSP survey using distributed optical fiber in China oilfield [10464-360]

10464 2C Fiber optic microphone with large dynamic range based on bi-fiber Fabry-Perot cavity [10464-530]

$104642 \mathrm{D}$ Fourier phase demodulation of interferometric fiber sensor [10464-2170]

$104642 \mathrm{E}$ Wavelength-switched phase interrogator for EFPI sensors with polarization self-calibrated [10464-2190]

$104642 \mathrm{~F}$ Simultaneous measurement for strain and temperature based on the twisted-tapering fiber structure [10464-2260]

$104642 \mathrm{G}$ A glucose concentration and temperature sensor based on long period fiber gratings induced by electric-arc discharge [10464-2340]

$104642 \mathrm{H} \quad \boldsymbol{\Phi}$-OTDR sensing system with bidirectional pumped fiber Raman amplifier and unbalanced MZ interferometer [10464-2550]

104642 Research on calibration method of downhole optical fiber temperature measurement and its application in SAGD well [10464-2630]

$104642 \mathrm{~J}$ Application of distributed optical fiber sensing technologies to the monitoring of leakage and abnormal disturbance of oil pipeline [10464-2730]

10464 2K Distributed acoustic sensing technique and its field trial in SAGD well [10464-2810]

$104642 \mathrm{~L}$ Distributed optical fiber temperature sensor and its application in high-temperature well logging [10464-2870] 
Proc. of SPIE Vol. 10464 1046401-8

Downloaded From: https://www.spiedigitallibrary.org/conference-proceedings-of-spie on 26 Apr 2023 Terms of Use: https://www.spiedigitallibrary.org/terms-of-use 


\section{Authors}

Numbers in the index correspond to the last two digits of the seven-digit citation identifier (CID) article numbering system used in Proceedings of SPIE. The first five digits reflect the volume number. Base 36 numbering is employed for the last two digits and indicates the order of articles within the volume. Numbers start with 00, 01, 02, 03, 04, 05, 06, 07, 08, 09, OA, OB...0Z, followed by 10-1Z, 20-2Z, etc.

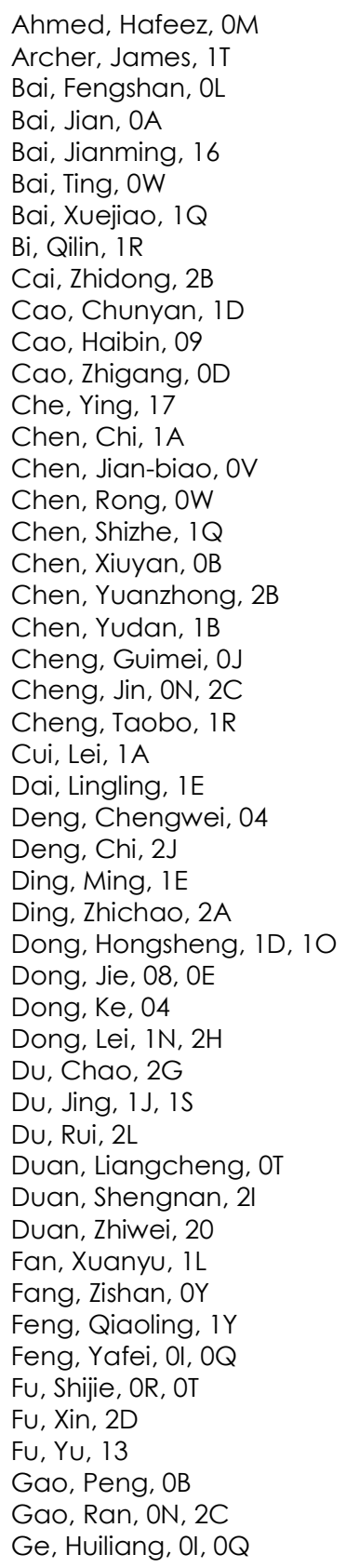

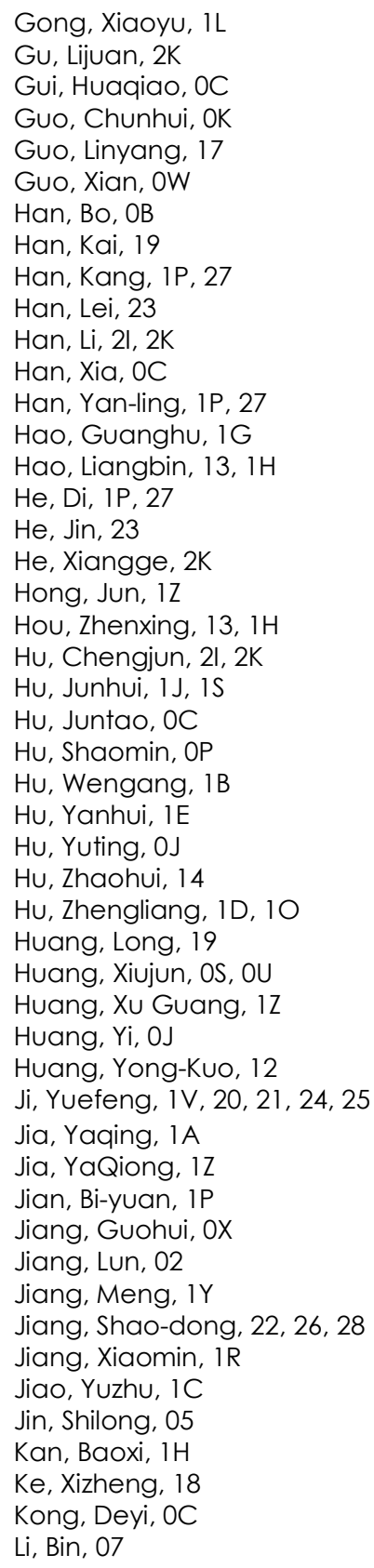


Li, Enbang, 1K, $1 \mathrm{~T}$

Li, Fei, 2B

Li, Hong, 11

Li, Hongfa, 20, 25

Li, Hui, 1V, 20, 21, 24, 25

Li, Jiajia, 2A

Li, Jing, 17

$\mathrm{Li}$, Jingnan, $1 \mathrm{~F}, 1 \mathrm{U}$

Li, Junyi, 2J, 2L

Li, Kai, $1 \mathrm{~N}$

Li, Kang, OD

Li, Ming, 28

Li, Na, 2L

Li, Pan, $1 Y$

Li, Shijian, 2I

Li, Shujuan, 00, 10, $1 \mathrm{G}$

Li, Shuo, OJ

Li, Yang, 1P, 27

Li, Yan-jie, OW

Li, Yanpeng, 2B

Li, Ying-chao, 02

Li, Yingying, 05, OP

Li, Yixuan, 24

Li, Yun Xia, OG

Li, ZhuLin, 1 Z

Liao, Xubo, OP

Lin, Jiping, OD

Lin, Yi, 20

Liu, Cheng, 2J

Liu, Congwei, 2B

Liu, Deming, 2D, 2F

Liu, Fei, 2K

Liu, Jianguo, OC

Liu, Junrong, 15

Liu, Lihai, 11

Liu, Shixuan, $1 Q$

Liu, Wende, 1A

Liu, Xiaoguang, IR

Liu, Xiao-hui, 1M, 26

Liu, Xiaoyong, 09

Liv, Yanfei, 06, OF

Liu, Yang, $1 \mathrm{~N}$

Liu, Yuze, 1V, 20, 24, 25

Liu, Zhi-chao, 03

Liv, Zhuang, 02

Lu, Dan-feng, ON, 2C

LU, Hanglin, 1J, $1 \mathrm{~S}$

LU, Jun, 1B

LÜ, Liang, OC

Lu, Pei, 09

Lu, Ping, 2D, 2F

Lu, Qilin, 14

Lu, Yang, 29

Lu, Zhiwei, 21

Luo, Hong, 2E

LUo, Hui, 05, OP

LUo, Hui, 2J

Luo, Jun Wen, OG, OH

Luo, Yuxiang, OK

LV, Jingsheng, 22
Lyu, Chunjian, IV

Ma, Long, $1 \mathrm{M}$

Ma, Pengfei, 19

Mao, Shaojuan, 1B

Meng, Ying, OA

Meng, Zhou, 29

Min, Li, 0O, 10, 1G, 28

$\mathrm{Mu}$, Weiwei, 11

$\mathrm{Ni}$, Jia-sheng, 0Z, 22, 26, 28

$\mathrm{Ni}$, Wenjun, $2 \mathrm{~F}$

Niu, Yanxiong, $1 \mathrm{E}$

Nuer, Maimaiti, 21

Pan, Yong, 2l, 2K

Peng, Gangding, 28

Peng, Ying-cheng, OW

Qi, HaiFeng, $0 Z$

Qi, Zhi-mei, ON, 2C

Qin, Feihu, OC

Qiu, Xiufen, 15

Quan, Wei, OY

Quan, Wenwen, $1 \mathrm{~J}, 1 \mathrm{~S}$

Ren, Jian-ying, OV

Ren, Yanfei, OA

Rong, LU, $1 \mathrm{U}$

Sang, Mei, 08, OE

Shan, Cong-miao, OV

Shao, Fei, OK

Shao, Jianxin, 09

Shao, Laipeng, $1 \mathrm{~J}, 1 \mathrm{~S}$

Shen, Heping, 15

Shen, Jingshi, OK, OS, OU

Sheng, Quan, OR, OT

Shi, Dele, OS, OU

Shi, Lei, OG, OH

Shi, Wei, OR, OT

Song, Haibing, $2 \mathrm{~L}$

Song, ZhiQiang, $0 Z$

Sun, Hao, 06, OF

Sun, Hua-yan, OV

Sun, Zhi-hui, 00, 10, 1G, 26, 28

Tan, Zhenkun, 18

Tian, Chunyu, $1 \mathrm{~W}$

Tian, Jiajun, $1 \mathrm{C}$

Tian, Ming, $2 \mathrm{H}$

Tian, Xiaozhong, OX

Tong, Shou-feng, 02

Tong, Xinlin, 04

Tu, Shan-Tung, 12

Tu, Yun, 12

Wang, Chang, 00, 0Z, 10, 1G, 22, 26, 28

Wang, Chao, 02

Wang, Chaodong, 11

Wang, Dachi, IW

Wang, Dayong, IF, IU

Wang, Fuyin, 2E

Wang, Hailiang, 13, 1H

Wang, Hong, IP, 27

Wang, Hongzhong, 1M

Wang, Huanqin, OC

Wang, Jiaan, 17 
Wang, Jian, OD

Wang, Jing, OM

Wang, Junlong, IY

Wang, Meng, $00,1 \mathrm{G}$

Wang, Ningbo, 21

Wang, Qi, 2G

Wang, Qiuli, 08, 0E

Wang, Tianli, OC

Wang, Xiaolin, 19

Wang, Xinlan, 17

Wang, Xuefeng, $1 \mathrm{H}, 1 \mathrm{Y}$

Wang, Yizhao, $1 Y$

Wang, Yubao, 06, OA, OF

Wang, Yulian, IW

Wang, Yunxin, IF, IU

Wang, Yunyun, 25

Wang, Zhiguo, 05, OP

Wei, Chang, IW

Wei, Jiahua, $\mathrm{OH}$

Wei, Yongfeng, OL

Wen, Hongqiao, 04

Wu, Guang-bin, 27

Wu, Junjun, 2B

Wu, Tianyin, $1 \mathrm{~J}, 1 \mathrm{~S}$

Wu, Wenfeng, 11

Xia, Ji, 2E

Xiao, Dong Rui, 12

Xiao, Maosen, 16

Xie, Liangping, $1 \mathrm{~L}$

Xing, Yuan-ding, OW

Xiong, Shuidong, 2E

Xiong, Yuchuan, 04

$X \cup$, Feng, $1 \mathrm{~W}$

$X U$, Jiahao, 1F, $1 U$

$X \cup$, Ling, $O M$

$X U, X i a o j u n, 19$

Xue, Yang, $0 \mathrm{G}, \mathrm{OH}$

Yan, Xingkui, $1 Q$

Yang, Biyao, $1 \mathrm{E}$

Yang, Bowen, IE

Yang, Dan, 14

Yang, Dengcai, 1F, $1 \mathrm{U}$

Yang, Jin-hua, 03

Yang, Ning, OK

Yang, Peng, OL

Yang, Xianglong, 1Q

Yang, Xiaojun, 2J, $2 \mathrm{~L}$

Yang, Yufei, 07

Yao, Jianquan, OR, OT

Yao, ShengXing, $1 Z$

Yao, Yong, $1 \mathrm{C}$

Yi, Duo, 2K

Yin, Jianling, 1B

Yin, Na, OJ

Yin, Yiheng, $1 \mathrm{E}$

Yu, Benhua, IN

Yu, Benli, OD, IW

Yu, Gang, 2B

Yu, Ji, OB

Yu, Wenpeng, $1 \mathrm{H}, 2 \mathrm{~J}$
Yu, Yuan, OX

Yu, Zhijie, 29

Yuan, Jie, 05, 2A

Zhai, Yueyang, OY

Zhan, Xiang, 05

Zhang, Bin, $1 \mathrm{~L}$

Zhang, Chunxi, 1L

Zhang, Cui, 04

Zhang, Cuicui, OS

Zhang, Fa-xiang, 00, 10, 1G, 22, 26, 28

Zhang, Guosheng, OD

Zhang, Haiwei, OR, OT

Zhang, Haiyan, 13, 1H

Zhang, Jian, OC

Zhang, Jiande, OK

Zhang, Jiangshan, 2D, 2F

Zhang, Jianliang, IA

Zhang, Keke, 1Q

Zhang, Lei, 13, 1H

Zhang, Liang, $2 \mathrm{H}$

Zhang, Min, 2K

Zhang, Qinghong, 2B

Zhang, Xian, 11, 14

Zhang, Xiao-lei, 00, 10, 1G, 26, 28

Zhang, Xudong, 23

Zhao, Haiying, 2B

Zhao, Meng, OX

Zhao, Qiang, 1Q

Zhao, Qingchao, 1M

Zhao, Wenan, 1M

Zhao, Xinghua, 11, 14

Zhao, Yan-zhong, OV

Zhao, Zhiwen, OM

Zhao, Zhong, $1 \mathrm{G}$

Zheng, Baichao, 13, 1H

Zheng, Huan, $\mathrm{Ol}, \mathrm{OQ}$

Zheng, Mingfang, 21

Zhong, Chenhao, 08, 0E

Zhong, Qiuwen, 1D, 10

Zhong, Xin, 1F, $1 \mathrm{U}$

Zhou, Binquan, 11, 14

Zhou, Jieyun, 11

Zhou, Tao, IF, IU

Zhou, Zichao, 19

Zhu, Meng, 16

Zhu, Xiaofei, 2J, 2L

Zhu, Yulong, $1 \mathrm{R}$

Zhu, Zhenmin, 09 
Proc. of SPIE Vol. 10464 1046401-12 Downloaded From: https://www.spiedigitallibrary.org/conference-proceedings-of-spie on 26 Apr 2023
Terms of Use: https://www.spiedigitallibrary.org/terms-of-use 


\title{
Conference Committees
}

\author{
Conference Chairs
}

Guangjun Zhang, Beihang University (China)

Byoungho Lee, Seoul National University (Korea, Republic of)

\section{Conference Committee}

Desheng Jiang, Wuhan University of Technology (China)

Hequan Wu, Chinese Academy of Engineering (China)

Jianquan Yao, Tianjin University (China)

Jianwei Pan, University of Science and Technology of China (China)

Junhao Chu, Shanghai Institute of Technical Physics, CAS (China)

Junen Yao, Beihang University (China)

Lijun Wang, Changchun Institute of Optics, Fine Mechanics and Physics, CAS (China)

Lin Li, The University of Manchester (United Kingdom)

Liwei Zhou, Beijing Institute of Technology (China)

Min Gu, RMIT University (Australia)

Shibin Jiang, AdValue Photonics Inc. (United States)

Toyohiko Yatagai, Utsunomiya University (Japan)

Wei Wang, Beijing Institute of Aerospace Control Devices, CASC (China)

Weidou Ni, Tsinghua University (China)

Zuyan Xu, Technical Institute of Physics \& Chemistry, CAS (China)

Program Committee

Anand Krishna Asundi, Nanyang Technological University (Singapore)

Bing Zhao, Jilin University (China)

Byoungho Lee, Seoul National University (Korea, Republic of)

Carl Nardell, Terra Bella (United States)

Chunhua Shen, The University of Adelaide (Australia)

Haimei Gong, Shanghai Institute of Technical Physics, CAS (China)

Honghai Liu, University of Portsmouth (United Kingdom)

Huaidong Yang, Tsinghua University (China)

Huijie Zhao, Beihang University (China)

Jannick Rolland, Institute of Optics, University of Rochester (United States)

Jin Lu, Tianjin Jinhang Institute of Technical Physics (China)

Jin Yu, Université Claude Bernard Lyon 1 (France)

Jinxue Wang, SPIE

Lijun Wang, Changchun Institute of Optics, Fine Mechanics and Physics, CAS (China)

Lin Li, The University of Manchester (United Kingdom)

Lan Jiang, Tsinghua University (China) 
Long Zhang, Shanghai Institute of Optics and Fine Mechanics, CAS (China)

Mengxia Xie, Beijing Normal University (China)

Min Gu, RMIT University (Australia)

Min Qiu, Zhejiang University (China)

Shibin Jiang, AdValve Photonics Inc. (United States)

Suijian Xue, National Astronomical Observatories, CAS (China)

Tsutomu Shimura, The University of Tokyo (Japan)

Wei Hang, Xiamen University (China)

Wei Wang, Beijing Institute of Aerospace Control Devices of CASC (China)

Weibiao Chen, Shanghai Institute of Optics and Fine Mechanics, CAS

(China)

Wolfgang Osten, Universität Stuttgart (Germany)

Xiandeng Hou, Sichuan University (China)

Xiangping Li, Jinan University (China)

Xiaocong Yuan, Shenzhen University (China)

Xiaodi Tan, Beijing Institute of Technology (China)

Yadong Jiang, University of Electronic Science and Technology of China (China)

Yanbiao Liao, Tsinghua University (China)

Yong Bi, Academy of Opto-Electronics, CAS (China)

Yongtian Wang, Beijing Institute of Technology (China)

Zhe Wang, Tsinghua University (China)

Zhiping Zhou, Peking University (China)

Session Chairs

1 Communication Network Reconfiguration and Software Definition Optical Transport Network

Tang Xiongyan, Unicom Labs (China)

2 Laser ablation, mass spectrometry, IR spectroscopy and instrumentation Dong Chenzhong, Northwest Normal University (China)

3 Development and Application of Distributed Optical Fiber Acoustic Sensor

He Zuyuan, Shanghai Jiaotong University (China)

4 Application of Fiber Bragg Grating Sensing Technology in Railway Traffic Safety Monitoring

Zhou Ciming, Wuhan University of Technology (China)

5 Application of Acoustic Wave Distribution Measurement (DAS) in Oil and Gas Field

Li Yingping, Shell (China)

6 Research and Application of Optical Fiber Grid Monitoring and Communication Fusion Technology

Zhang Zhiguo, Beijing University of Posts and Telecommunications (China) 


\section{Introduction}

Applied Optics and Photonics China (AOPC2017) is the annual conference of the CSOE, and one of the largest academic and industry activities in the field of optical and optoelectronic technology in China. The organization committee has built a platform of academic exchanges, industry exhibitions, and cooperation negotiations in one. There are 8 technical conferences, 7 themes of the Exhibition and approximately 600 technical presentations. We sincerely hope that the research and development of optoelectronic technology are promoted, and the international cooperation between industry and the optical and optoelectronic fields are enhanced.

AOPC2017 is technically co-sponsored by the Chinese Society for Optical Engineering, the Optical Society of Korea (OSK), Optics and Photonics Society of Singapore (OPSS), European Optical Society (EOS), Optical Society of Japan (OSJ) and SPIE. There are also 60 cooperative organizers to support the conference. We received over 1209 contributions from more than 15 countries, including the United States, the United Kingdom, Germany, France, Spain, Australia, Canada, Mexico, Brazil, Japan, Korea, Thailand, Singapore, the Russian Federation, China, and more. There are more than 700 presentations published in the Proceedings of SPIE. After careful discussion, we suggested four keynote speeches which are presented by famous scientists from Germany, Australia, Japan and China. 138 excellent invited talks were presented, 45 are from outside of China. Their presentations reflect first-class research in the field of optics and photonics technology. On behalf of the Organization Committee of AOPC, I express thanks to all the invited speakers and authors for their contributions and support of the conference.

Finally, on behalf of Prof. Zhuang Songlin, and other co-chairmen, and the Organization Committee of AOPC, I would like to heartily thank our sponsors and cooperating organizers for all they have done for the conference, the participants and friends for their interests and efforts in helping us to make the conference a success, the program committee for their effective work and valuable advice, and especially the AOPC2017 Secretariat and the staff of SPIE for their tireless effort and outstanding services in preparing the conference and publishing the Proceedings.

We wish AOPC2017 great success! Hope to see you next year!

\section{Guofan Jin}


Proc. of SPIE Vol. 10464 1046401-16 Downloaded From: https://www.spiedigitallibrary.org/conference-proceedings-of-spie on 26 Apr 2023
Terms of Use: https://www.spiedigitallibrary.org/terms-of-use 